к.т.н., дочент, дочент кафедры «Автоматизация технологических процессов», ФГБОУ ВО «Ангарский государственный технический университет», тел.: +7 (3955) 67-89-15, e-mail: nataly_06@inbox.ru

Крапчетова Ольга Сергеевна,

директор Ангарского образовательного иентра, ФГБОУ ВО «Иркутский государственный университет», тел.: +7 (3955) 53-26-43 e-mail:dop.obr@angarsk.isu.ru

\author{
ФОРМИРОВАНИЕ ЭЛЕКТРОННОГО ОБРАЗОВАТЕЛЬНОГО РЕСУРСА НА \\ ПРИМЕРЕ ДИСЦИПЛИНЫ "АВТОМАТИЗАЦИЯ УПРАВЛЕНИЯ ЖИЗНЕННЫМ \\ ЦИКЛОМ ПРОДУКЦИИ"
}

Kuzmenko N.V., Krapchetova O.S.

\title{
FORMATION OF ELECTRONIC EDUCATIONAL RESOURCE ON THE EXAMPLE OF THE DISCIPLINE "AUTOMATION OF MANAGEMENT OF A LIFE PRODUCT CYCLE"
}

Аннотация. Электронный образовательный ресурс с применением современных информационных технологий является необходимым компонентом образовательной системы. Знание основных понятий жизненного иикла продукции и необходимости автоматизации управления жизненным ииклом в промышленности, особенно на опасных нефтехимических производствах, является в настоящее время важной составляющей обучения студентов технических направлений подготовки высшего образования.

Ключевые слова: электронный образовательный ресурс, жизненный ичикл продукции, автоматизация управления жизненным ициклом.

Abstract. An electronic educational resource using modern information technologies is a necessary component of the educational system. Knowledge of the basic concepts of the product life cycle and the need for automation of life cycle management in industry, especially in hazardous petrochemical industries, is currently an important component of training students in technical areas of higher education.

Keywords: electronic educational resource, product life cycle, automation of life cycle management.

В настоящее время постоянно разрабатываемые новые информационные технологии и внедряемые новые образовательные стандарты с обязательными формами и методами обучения требуют создания современных электронных образовательных ресурсов (ЭОР), соответствующих этим новшествам и актуальным жизненным реалиям.

Стандарты высшего образования разрабатываются на основе профессиональных стандартов соответствующих видов профессиональной деятельности, что требует иного подхода к ЭОР, к его форме и содержанию.

При формировании ЭОР необходимо учитывать положения стандартов, относящихся к сфере электронного обучения и электронной образовательной среды вуза. В настоящее время действуют различные стандарты, регулирующие создание и применение ЭОР, как общей направленности [1], устанавливающие основные положения по направлению «электронные образовательные ресурсы», так и более специализированные, например, посвящённые организации виртуального эксперимента (ВЭ) [2]. Данный стандарт предназначен для образовательных организаций, реализующих образовательные программы с применением электронного обучения и дистанционных образовательных технологий.

Применение ЭОР в обучении позволяет использовать различные формы подачи информации, наиболее подходящие средства контроля и самоконтроля на разных этапах изучения, формы заданий, позволяющих закреплять знания, формировать навыки.

ЭОР разрабатывается для размещения в электронно-информационной образовательной среде вуза (ЭИОС), т.е. материал представляется в различных видах, что позволяет изучать эту дисциплину при различных формах обучения (дистанционно, заочно). 
ВЭ при лабораторных исследованиях и экспериментах: проводится с использованием виртуальной среды или в режиме удаленного доступа. Проведение виртуального эксперимента возможно в составе ЭИОС образовательных организаций.

Это достигается применением разработанных в АнГТУ и внедренных в учебный процесс компьютерных тренажеров-имитаторов (КТИ) для обучения оперативного персонала технологических установок [3]. КТИ нацелены на безопасное управление различными технологическими объектами, в частности, энерготехнологическими котлами, парками хранения сжиженных углеводородов и пр. Модель технологического процесса в КТИ представляет собой максимально приближенную к технологическим процессам динамическую математическую модель, основанную на полном и детальном описании процесса: нелинейными дифференциальными уравнениями состояния фазовых переходов, тепло- и массообменных процессов, теплового и материального баланса компонентов продуктов, гидродинамики и гидравлики. В КТИ эмулируется работа систем блокировок и противоаварийной защиты. На рисунке 1 представлена интерактивная экранная форма участка технологического процесса с размещенными на ней динамическими элементами с возможностью воздействия на полевую арматуру (ручные задвижки). Одна из экранных форм, действующей на установке и сымитированной в КТИ, распределенной системы управления (РСУ) показана на рисунке 2.

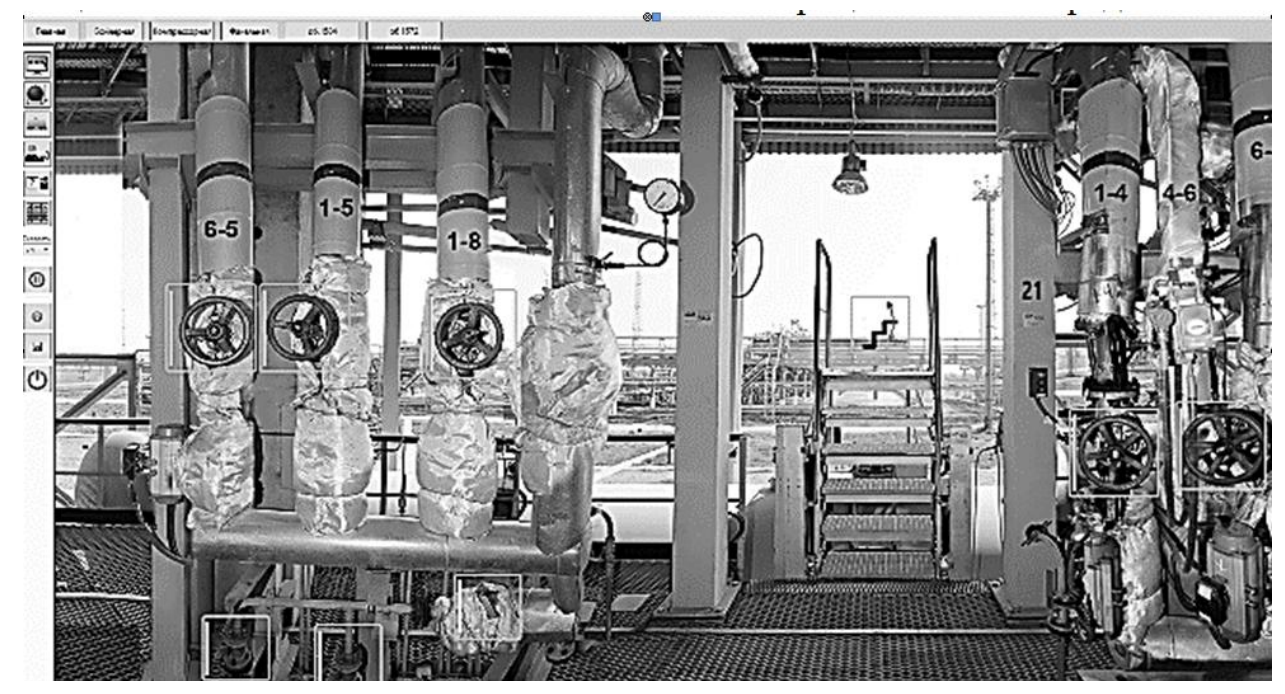

Рисунок 1 - Фрагмент экранной формы полевого оборудования КТИ

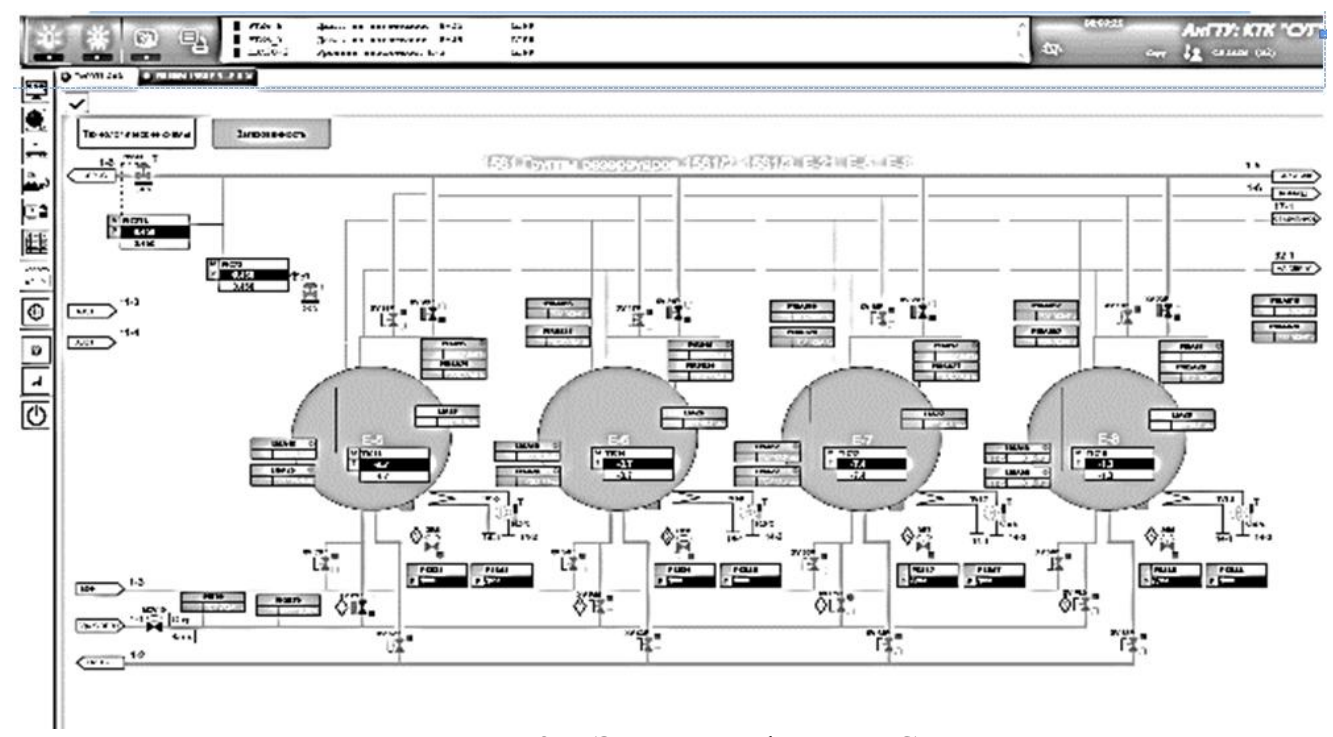

Рисунок 2 - Экранная форма РСУ 
Информационное обеспечение КТИ включает в себя средства и технологию организации и реорганизации базы данных моделирования, методы логической и физической организации массивов, формы документов, описывающих процесс моделирования и его результаты.

ЭОР с применением современных информационных технологий разработан по дисциплине «Автоматизация управления жизненным циклом продукции» для подготовки бакалавров по направлению «Автоматизация технологических процессов и производств», в таблице 1 представлена общая трудоемкость дисциплины по учебному плану.

Таблица 1 - Трудоемкость дисциплины

\begin{tabular}{l|c|}
\hline \multicolumn{1}{|c|}{ Вид учебной работы } & Всего, час. \\
\hline Аудиторные занятия (всего) & 54 \\
\hline В том числе: & 18 \\
\hline Лекции \\
\hline Практические занятия (П3) & 36 \\
\hline $\begin{array}{l}\text { Самостоятельная работа (все- } \\
\text { го) }\end{array}$ & 18 \\
\hline В том числе: \\
$\begin{array}{l}\text { Изучение лекционного мате- } \\
\text { риала и подготовка к практи- } \\
\text { ческим занятиям }\end{array}$ & 10 \\
\hline Написание реферата & 8 \\
\hline Итого: & 72 \\
\hline
\end{tabular}

Основные разделы дисциплины содержат следующий материал: основные понятия и этапы жизненного цикла, информационная поддержка и автоматизация управления жизненным циклом продукции (ЖЦП) на различных этапах, что помогает формировать у студентов понимание важности управления ЖЦП, ясное представление каждого этапа и возможностей автоматизации разных этапов.

Жизненный цикл продукта [4] представляет собой совокупность процессов, выполняемых от момента выявления потребностей общества в определенной продукции до момента удовлетворения этих потребностей и утилизации продукта.

Поиск методов и средств для увеличения срока стадии эксплуатации, не допуская стадии старения (физического и морального), является в настоящее время актуальной задачей производителей продукции.

Информационное взаимодействие субъектов, участвующих в поддержке жиз- ненного цикла (ЖЦ), должно осуществляться в едином информационном пространстве (ЕИП).

Для разрушения коммуникационных барьеров и реализации концепции непрерывной информационной поддержки жизненного цикла изделия или продукта (Continuous Acquisition and Life Cycle Support - CALS) необходимо создать ЕИП для всех участников управления ЖЦ, в том числе и на этапе эксплуатации.

Этапы жизненного цикла представлены на рисунке 3.

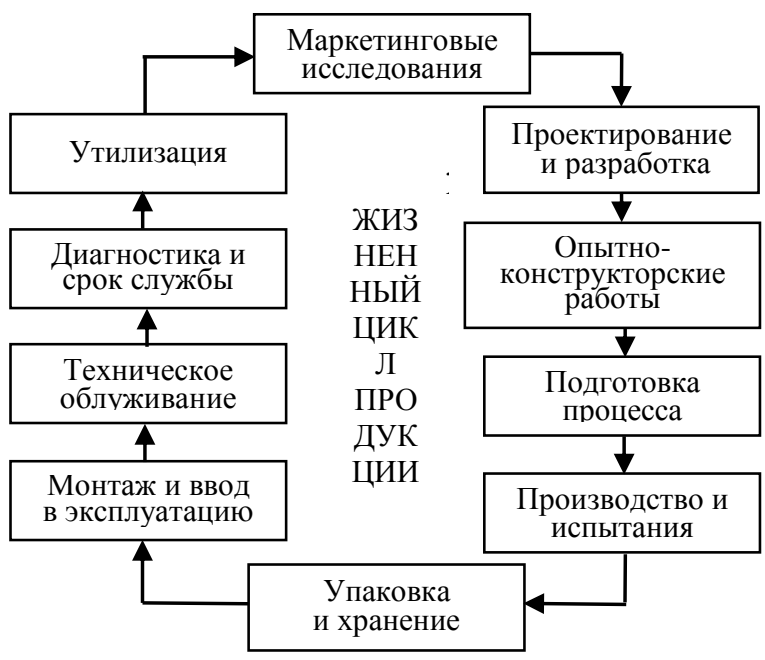

Рисунок 3 - Этапы жизненного цикла

Для управления ЖЦ в ЕИП необходимо реализовать следующие функции:

- возможность аккумулировать всю информацию об изделии;

- быть единственным источником данных о нем (прямой обмен данными между участниками ЖЦ исключен);

- формироваться на основе международных, государственных и отраслевых стандартов.

ЕИП создается с помощью программно-аппаратных средств, уже имеющихся у участников управления ЖЦ.

Организация ЕИП осуществляется в два этапа:

I этап - автоматизация отдельных процессов ЖЦ изделия и представление данных на них в электронном виде;

II этап - интеграция автоматизированных процессов и относящихся к ним данных.

ЕИП может быть создано для структур разного уровня: от отдельного подразделения до предприятия или корпорации. Управление 
данными в информационном пространстве, едином для различных автоматизированных систем, возлагается на систему управления жизненным циклом продукции, реализующую технологии PLM (Product Lifecycle Management). Технологии PLM объединяют методики и средства информационной поддержки изделий на протяжении всех этапов жизненного цикла. Характерной особенностью PLM является обеспечение взаимодействия как средств автоматизации разных производителей, так и различных автоматизированных систем многих предприятий, то есть технологий PLM.

Технологии PLM являются основой, интегрирующей информационное пространство, в котором функционируют различные системы, такие как системы автоматизированного проектирования, планирования и управления предприятием, управления проектными данными, управления цепочками поставок, расчетов и инженерного анализа, а также другие автоматизированные системы предприятий.

Примером необходимости и важности проведения жесткого контроля ЖЦ на промышленных предприятиях опасных производств является наглядная иллюстрация жизненного цикла трубопроводов технологической установки [5].

На рисунке 4 приведены результаты анализа срока службы трубопроводов установки ректификации метанола, из которого видно, что максимальное количество трубопроводов введено в эксплуатацию в 1960 году.

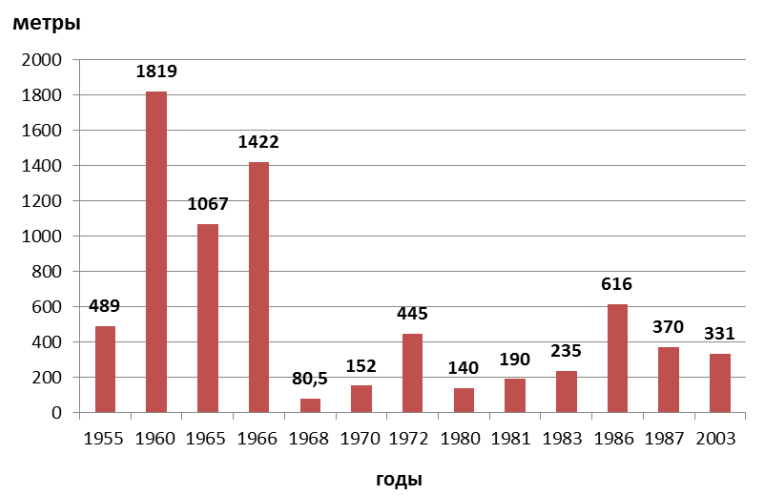

Рисунок 4 - Срок службы трубопроводов

Общая длина трубопроводов составляет 7350 м. Количество трубопроводов, которые находятся в эксплуатации более 55 лет составляет свыше $30 \%$, более 40 лет - свыше $40 \%$ от общего количества, и отсутствие своевременных мероприятий по контролю ЖЦ трубопроводов может привести к техногенной катастрофе [6].

При изучении дисциплины студентам необходимо работать с большими объёмами информации, вынесенными на самостоятельную работу, различными компьютерными программами, что требует нового подхода к созданию современных ЭОР.

На рисунке 5 представлена структура электронного образовательного ресурса по дисциплине «Автоматизация управления жизненным циклом продукции».

Обязательны элементом ЭОР является рабочая программа дисциплины, которая дает полную информацию о целях, задачах и необходимых знаниях в результате изучения дисциплины.

Различные виды представления теоретического материала - конспект лекций, учебное пособие, инфографика по основным положениям темы, аудио- и видеолекции, ссылки на ресурсы интернета и т.д. - дают широкие возможности для самостоятельной работы.

Необходимо отметить, что электронный образовательный ресурс возможно дополнять новыми учебными материалами.

Так, для дальнейшей работы с рассматриваемым ЭОР запланировано внедрение такой формы подачи учебного материала как виртуальный эксперимент с использованием виртуальных тренажёров.

Для подготовки к практическим занятиям ЭОР содержит задания и методические рекомендации для выполнения. При этом для лучшего усвоения теоретического и практического материала задания также создаются в разных видах, что позволяет как контролировать освоение материала, в том числе проводить самоконтроль, так и развивать навыки и умения.

Использование программного обеспечения для создания баз данных контроля жизненного цикла для управления работой структурного подразделения предприятия (технологического участка, установки или цеха) дает возможность применения лекционного материала для практических работ.

Фонд оценочных средств (ФОС) и знание этапов промежуточного и итогового контроля дает возможность студенту провести своевременную подготовку.

ФОС содержит:

- контрольные вопросы для текущего 
контроля знаний лекционного материала;

- темы для написания реферата, пример выполнения реферата;

- контрольные вопросы для итогового контроля.
Учебные пакеты прикладных программ применимы для самостоятельной работы студента (СРС).

ЭОР является обязательной и важной составляющей образовательного процесса.

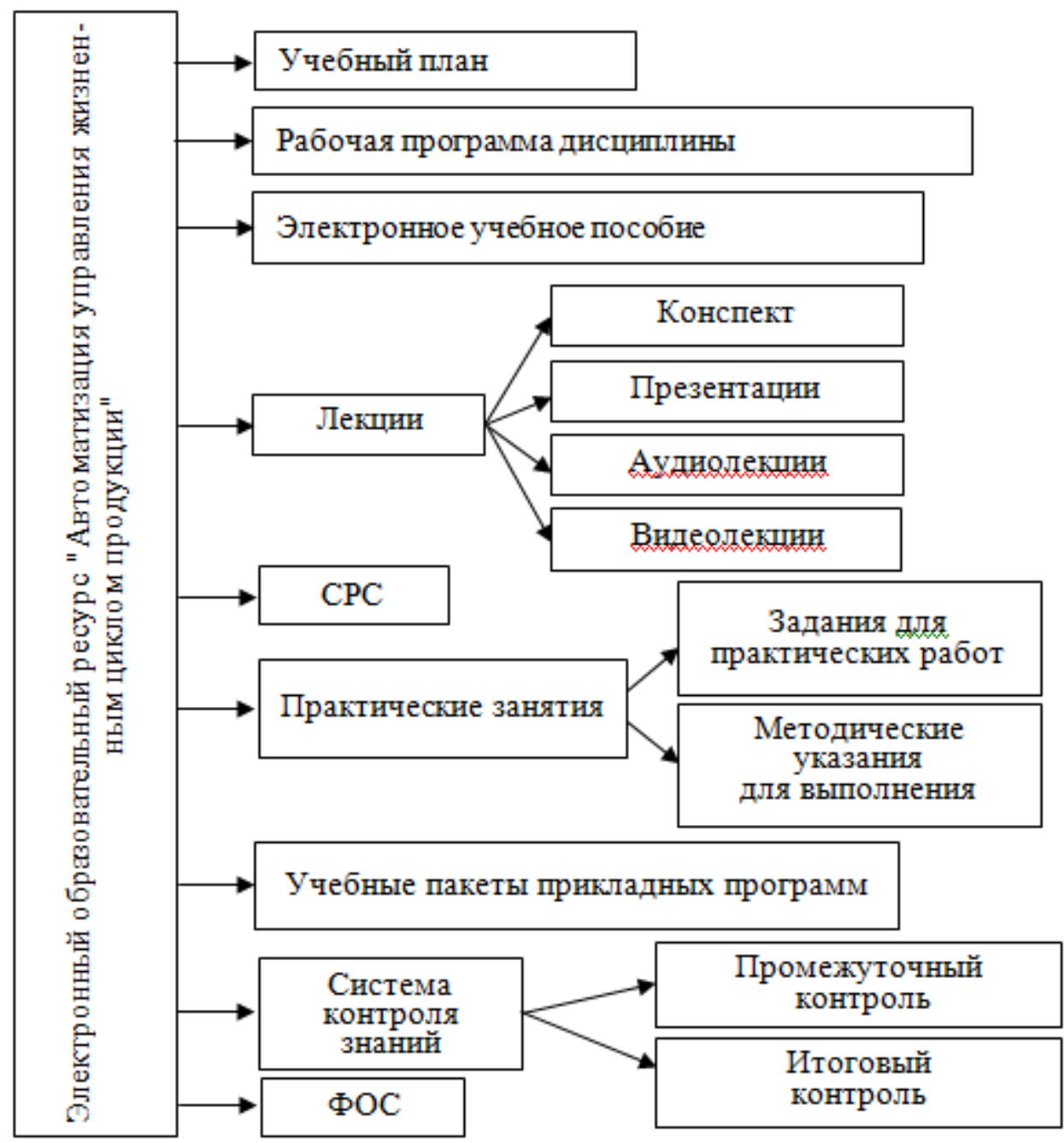

Рисунок 5 - Структура электронного образовательного ресурса по дисциплине «Автоматизация управления жизненным циклом продукции»

\section{СПИСОК ЛИТЕРАТУРЫ}

1. ГОСТ Р 53620-2009 Электронные образовательные ресурсы. Общие положения. М.: Стандартинформ, 2018. - 12 с.

2. ГОСТ Р 57721-2017 Информационнокоммуникационные технологии в образовании. Эксперимент виртуальный. Общие положения. - М.: ФГУП «Стандартинформ», 2018. $-11 \mathrm{c}$.

3. Благодарный Н.С., Колмогоров А.Г., Кобозев В.Ю., Кривов М.В., Мороз Н.В. Компьютерные тренажёры-имитаторы для обучения персонала безаварийной эксплуатации энерготехнологических котлов //
Сборник научных трудов. - Ангарск: Изд-во АГТА, 2015. - C.7-14.

4. ГОСТ Р 53791-2010 Ресурсосбережение. Стадии жизненного цикла изделий производственно-технического назначения.

М.: Стандартинформ, 2011. - 12 с.

5. Кузьменко Н.В., Куликов В.В., Юрьев Ю.Ю. Основные этапы разработки методики инфракрасной диагностики для контроля состояния технологических трубопроводов // Сборник научных трудов Ангарского государственного технического университета. Ангарск: Изд-во АнГТУ, 2018. - С. 93-96. 